Archived version from NCDOCKS Institutional Repository http://libres.uncg.edu/ir/asu/

\title{
Appalachïan
}

B O O N E, NORT H C A R O L I A

\section{Environmental Nursing: Leaders Reflect On The 50th Anniversary Of Earth Day}

\author{
By: Phoebe Pollitt, Barbara Sattler, Patricia G. Butterfield, Laura Anderko, Charlotte Brody, Lillian \\ Mood, Katie Huffling, Elizabeth Schenk, and Katsi Cook
}

\begin{abstract}
The notion that "it takes a village" rings particularly true for the incredible progress that a small village of environmental health nursing leaders has helped to accomplish. Many nurses who come to environmental health also have had an abiding relationship to "nature" which in many cases has meant the great outdoors-our experiences hiking and camping, on our farms, and in gardens. For some nurses protecting our land, air, and water is a natural extension of this first relationship with nature. As nurses, we learn that our environments also include indoor environments, such as our workplaces, schools, and institutions. Our environments are also our neighborhoods and communities in relation to nearby industries, hazardous waste sites, aerial spraying of pesticides, and oil/gas wells. And as nurses we weave our knowledge about the human body, vulnerable populations, and health disparities into our learning so that environmental health and environmental justice become the goal posts for our newly integrated environmental health and nursing efforts. The seminal report "Nursing, Health \& Environment," prepared for the Institute of Medicine in 1995, identified four key areas for nursing focus. Since then, these are addressed as the REAP Framework: Research, Education, Advocacy, and Practice. This article contains a compendium of stories about and by seven nursing leaders and one Indigenous midwife who have written, worked, and led in environmental health and nursing over the past 50 years. It is our way of sharing nurses' history in these endeavors and celebrating it in the context of this month's 50th anniversary of Earth Day.
\end{abstract}

Pollitt, P, Sattler, B, Butterfield, PG, et al. Environmental nursing: Leaders reflect on the 50th anniversary of Earth Day. Public Health Nurs. 2020; 37: 614- 625. https://doi.org/10.1111/phn.12703. Publisher version of record available at: https://onlinelibrary.wiley.com/doi/10.1111/phn.12703 


\title{
Environmental nursing: Leaders reflect on the 50th anniversary of Earth Day
}

\author{
Phoebe Pollitt PhD, RN, Associate Professor of Nursing/RETIRED ${ }^{1}$ | \\ Barbara Sattler MPH, DrPH, RN, FAAN, Professor ${ }^{2}$ । \\ Patricia G. Butterfield PhD, RN, FAAN, Professor ${ }^{3}$ (D) | Laura Anderko PhD, RN, Professor ${ }^{4}$ | \\ Charlotte Brody RN, Vice President ${ }^{5}$ | Lillian Mood MPH, RN, FAAN, Chair ${ }^{6}$ | \\ Katie Huffling MS, RN, CNM, FAAN, Executive Director ${ }^{7}$ (D) । \\ Elizabeth Schenk PhD, MHI, RN-BC, FAAN, Nurse Scientist and Sustainability Coordinator ${ }^{8}$ । \\ Katsi Cook Founder, Co-founding member ${ }^{9,10}$ \\ ${ }^{1}$ Appalachian State University, Boone, NC, USA \\ ${ }^{2}$ University of San Francisco School of Nursing and Health Professionals, San Francisco, CA, USA \\ ${ }^{3}$ Washington State University Elson S. Floyd College of Medicine, Spokane, WA, USA \\ ${ }^{4}$ Robert and Kathleen Scanlon Endowed Chair in Values Based Health Care Georgetown School of Nursing \& Health Studies, Washington, DC, USA \\ ${ }^{5}$ Health Initiatives, BlueGreen Alliance, Washington, DC, USA \\ ${ }^{6}$ Institute of Medicine Study Committee and Co-Editor, IOM Report: Nursing, Washington, DC, USA \\ ${ }^{7}$ Alliance of Nurses for Healthy Environments, MD, USA \\ ${ }^{8}$ Providence-WSU Nurse Scientist/Sustainability Coordinator, Providence St. Patrick Hospital, Missoula, MT, USA \\ ${ }^{9}$ First Environment Collaborative, Hogansburg, NY, USA \\ ${ }^{10}$ National Aboriginal Council of Midwives, Montreal, QC, USA \\ Correspondence \\ Katie Huffling, 2901 Shepherd St., Mount Rainier, MD 20712, USA. \\ Email: katie@envirn.org
}

Whoa, ah, mercy mercy me

Oh things ain't what they used to be, no no

Where did all the blue skies go?

Poison is the wind that blows from the north and south

and east

Whoa mercy, mercy me,

Oh things ain't what they used to be, no no

Oil wasted on the oceans and upon our seas, fish full of mercury

Ah, oh mercy, mercy me

Ah things ain't what they used to be, no no

Radiation underground and in the sky

Animals and birds who live nearby are dying

Oh mercy, mercy me

Oh things ain't what they used to be
What about this overcrowded land

How much more abuse from man can she stand?

Marvin Gaye, 1971

\section{1 | INTRODUCTION}

The notion that "it takes a village" rings particularly true for the incredible progress that a small village of environmental health nursing leaders has helped to accomplish. Many nurses who come to environmental health also have had an abiding relationship to "nature" which in many cases has meant the great outdoors-our experiences hiking and camping, on our farms, and in gardens. For some nurses protecting our land, air, and water is a natural extension of this first relationship with nature. As nurses, we learn that our environments also include indoor environments, such as our workplaces, schools, and institutions. Our environments are also our neighborhoods and 
communities in relation to nearby industries, hazardous waste sites, aerial spraying of pesticides, and oil/gas wells. And as nurses we weave our knowledge about the human body, vulnerable populations, and health disparities into our learning so that environmental health and environmental justice become the goal posts for our newly integrated environmental health and nursing efforts.

The seminal report "Nursing, Health \& Environment," prepared for the Institute of Medicine in 1995, identified four key areas for nursing focus. Since then, these are addressed as the REAP Framework: Research, Education, Advocacy, and Practice. This article contains a compendium of stories about and by seven nursing leaders and one Indigenous midwife who have written, worked, and led in environmental health and nursing over the past 50 years. It is our way of sharing nurses' history in these endeavors and celebrating it in the context of this month's 50th anniversary of Earth Day.

\section{I RESEARCH}

\subsection{Healing the Earth}

\section{Dr. Laura Anderko, PhD, RN}

Professor, Robert and Kathleen Scanlon Endowed Chair in Values Based Health Care at Georgetown's School of Nursing \& Health Studies

My birthday is Earth Day, so my love for the environment seems to be my DNA. Growing up in Chicago, I can remember the feeling of sadness as buses spewed clouds of black smoke into the neighborhood. The Clean Air Act of 1970 brought relief. As a student nurse in the 1970s (the decade when Earth Day was established), the curriculum was completely void of content about the connection between our earth and our health. As a public health nurse, the turning point that began my journey into environmental health was a home visit to a young mother who had given birth to a baby without a brain. Although the mother had received prenatal care and had taken care of herself, her baby was dying from an unknown cause. I noticed the home was located in a highly polluted area near an industrial site. I began to seek answers to the possible causes for the baby's impending demise and learned about the various chemicals that could lead to neurodevelopmental damage.

I have learned that partnerships are the key to success in driving healthy public policy. Over time, the general public has been one of my most important collaborators-regardless of the population at risk, environmental health issues identified, and/or policy addressed. Grassroot efforts to mobilize communities to support public policy that protects our environment has been critical for improving the public's health. These partnerships were crucial for policy gains impacting climate and health (such as the reduction in carbon pollution)-and were highlighted when I received the White House Champion of Change award from the Obama Administration for my work to protect public health in a changing climate.

During my career, I have focused on a range of environmental exposures and their impacts on the public's health, ranging from methylmercury poisoning associated with fish consumption to climate change. Today, as Director of the Mid-Atlantic Center for Children's Health and the Environment (MACCHE) and the first nurse to lead a Pediatric Environmental Health Specialty Unit (PEHSU), serving Delaware, District of Columbia, Maryland, Pennsylvania, Virginia, and West Virginia, where my focus is on fulfilling its mission: to educate health professionals and the general public on a wide range of environmental issues impacting reproductive and children's health. Over the past 5 years, MACCHE has been successful in meeting this goal, educating thousands of health professionals and community members annually.

I have found nurses to be great communicators and polls have consistently indicated that nursing is the most trusted profession. We need to acknowledge and utilize this strength to educate and advocate for public policy that supports healthy environments and healthy people. The nursing profession must also shift from traditional models of care that are human centered to one that embraces an ecocentric or Earth-centered model of caring. Healing the Earth will ultimately, heal humanity.

\section{2 | Thinking Upstream}

\section{Dr. Patricia Butterfield, PhD, RN, FAAN \\ Professor at the Elson S. Floyd College of Medicine, Washington State University, Spokane}

I was excited about the project from the beginning; it seemed quite out of the box. It was the summer of 1987, and I was in in-between mode. I had already made the decision to leave Idaho and move to Portland to enter doctoral study at Oregon Health Sciences University (OHSU). Before leaving Boise, I was asked to collect data addressing the capability of Idaho towns to respond to hazardous material incidents in their area. Most likely this would be a train derailment or truck spill. Over the next several weeks, I visited fire departments, police stations, and civil defense units from the south to the northern tip of the state. What I found was tremendous variability in small town response capability. Some towns had sophisticated equipment and were shovel-ready (literally) for an environmental health incident; however, other communities lacked anything beyond dust masks. Had I recognized it, I could have learned an important life lesson early on: there are haves and have nots in regard to environmental assets. Conversely there are haves and have nots in regard to risk. To a large degree that imbalance predetermines which doors to health opportunity open throughout one's lifetime. Some families and communities are systematically disadvantaged by others' greed and hubris. Other communities, typically through money and proximity to power, are spared. Those children in the latter group have the opportunity to reach their full potential, their health not dampened by serial exposures to lead, solvents, pesticides, and more. In my first summer in environmental health I learned that risks and riches are not equitably distributed throughout our nation. Little did I know at the time, but that summer set the stage for my life's work promoting environmental health and justice.

While at OHSU I dabbled in occupational and environmental health for a year; the program was excellent, and faculty was opening my eyes. 
In theory class, I penned a final paper titled, "Thinking Upstream" and was pleased to have it receive an enthusiastic response from Drs. Julia Brown and Chris Tanner. With their encouragement I submitted the manuscript to Advances in Nursing Science. Its publication in 1990 bolstered my confidence as a writer and concept weaver. Even better was the response from editor Peggy Chinn, who noted, much to my chagrin, that "Thinking Upstream" would change nursing. Lo and behold, it did. Thinking upstream is based on my reconstruction of a parable told by physician J.B. McKinlay. In the parable, McKinlay recounts a dream in which he sees a person caught in a river's torrent. McKinlay dives in to rescue them, only to see another, then another, then more people drifting downstream. When asked by his friend what was pushing them into the river, McKinlay noted that he had no idea because he never had time to look upstream (at the real causes of disease). In the seminal 1990 publication, I used the upstream parable to critique nursing practices that overemphasized short-term band-aid fixes at the expense of working to reduce upstream risk factors addressing poverty, housing, and societal-level imbalances in power. Initially launched by my words, others across nursing extended its reach by applying its precepts to a variety of issues. Upstream thinking obtained traction because, first and foremost, it resonated with nurses. Upstream gave voice and form to population health because it was intuitively understood by so many clinicians. Like me, they too were mystified by health care's preoccupation with band-aid fixes and its blind eye to the sea of economic and environmental risks that needed to be addressed if health was to be restored. I had the honor of bringing upstream thinking to nursing, tailoring, and applying the ideas of physician J.B. McKinlay to align with the interests of nurses. Publishing upstream as a doctoral student provided me with many years of conversation and insight, as other students sought me out at conferences and the like, telling me their own upstream insights. Although not intentionally literal, the connection of upstream thinking to environmental issues always felt hand in glove to me. It is my foundational way of seeing the world.

Practical science is my other love. Agnostic to method, I'm drawn to messy environmental health questions because...to me, all good questions are inherently messy. Very early on I was a nighttime public health nurse for the City and County of Denver, somewhat analogous to a rapid response team for home visits. Most evenings I did five home visits in 4 hours, traversing the city to provide wound care for anyone that Denver General wanted out the door. From this work I developed an appreciation of the central role that homes play in environmental health exposures, many of which would not be picked up using a canned exposure history tool. That job formed the basis of my scientific interests.

A stunning opportunity opened the door. While I was at OHSU Dean Carol Lindeman had a conversation with Dr. Peter Spencer, the newly arrived Director of OHSU's Center for Research on Occupational and Environmental Toxicology (CROET). Peter mentioned that he needed to hire someone to make home visits focused on identifying environmental exposures linked to neurodegenerative diseases. That conversation, along with ongoing support from those two visionary mentors, led to 5 incredible years at CROET, having my dissertation findings published in Neurology, and results from my postdoctoral work published in the American Journal of Industrial
Medicine. What I learned from that work was that a thorough understanding of people's exposures came only by conducting a detailed assessment and asking probe-based questions addressing hobbies, cottage industry work, and atypical events. I learned it was possible to reconstruct lifetime exposure histories and then find biologically plausible associations between those exposures and disease. I believe that much more of that work needs to happen today if we are to unlock mysteries addressing disease etiology. It is important work because those affected want (and deserve) to know, "Why did this happen to me?" and "What can I do protect others?"

Being in the West has been a gift. Following my years in Oregon I worked at Montana State University and the University of Washington before settling in at Washington State University (WSU). Together, valued colleagues and I developed and tested a risk reduction intervention aimed at reducing multiple environmental health risks to rural low-income families. I subsequently served as the Principal Investigator for the Grant County site for the National Children's Study. The former (i.e., risk reduction study) was the first R01-level National Institute for Nursing Research study ever funded; it tested a public health nurse-delivered environmental health intervention in homes.

Serving as Dean of Nursing at WSU and then working in our newly created medical school has given me the opportunity to hear the wisdom of colleagues and students across disciplines. It is what gives me a sense of reassurance about the future. There are ground-breaking innovations being advanced by a new generation of scientists and clinicians. It is plain to see that those who are poor and powerless bear a disproportionate share of environmental burden; changing that dynamic will require speaking truth to power in both policy and science. In the United States it will be imperative to assure that Donald Trump does not have a second term of office; his assault on environmental protections for air, water, and the land are unprecedented in scope and must be reversed. We must also redouble our efforts to bring voice to all constituencies for environmental health.

In a previous essay I invoked the wisdom of Peggy Chinn and others by stating what I consider to be the most salient and urgent question of our time: "The future will ask, what did you do?" In the realms of science, truth telling, and resistance there is so much to be done. By focusing efforts upstream we will restore balance to our people and planet.

\section{3 | EDUCATION}

\subsection{Designing The Future}

\section{Barbara Sattler, RN, MPH, DrPH, FAAN \\ Professor, University of San Francisco, School of Nursing and Health Professionals \\ Board Member of the Alliance of Nurses for Healthy Environments}

One of my earliest concerns about the environment came in 1969 when my high school environmental club began to look at the air pollution, the brown air, in the Santa Clara Valley. We met with people 
from the regulatory agencies to figure out how they addressed air pollution, which we felt was inadequate, and then we began to work with organizers of the first Earth Day that was held in April 1970.

Once I became a Registered Nurse and was working in critical care, I also was very involved in my nursing union and became part of the contract negotiation team. This experience helped me to understand the importance of collective action, the power of organizing, the art of negotiations, and how to work strategically to accomplish goals. It started me thinking about who is "in charge" and who "has power." Understanding these two questions has been incredibly important in addressing environmental health. Once I started working on chemical policies, I added the additional question of who benefits, usually in terms of money, from processes and pollution that harm workers and communities.

After several years of bedside nursing, I went back to school for my Masters in Public Health and then became the Executive Director of a small nonprofit, MaryCOSH (Maryland Committee on Occupational Safety and Health) that worked on a variety of occupational health issues. My main focus was helping to pass a statewide worker right to know law so that workers could find information about the toxic chemicals that they were working with. Our success was largely a function of the diversity of the coalition that we created which included unionized workers, firefighters, health professionals, and nonprofit organizations like Clean Water Action and the American Lung Association. Learning to play with people and organizations that have different agendas and yet finding a common goal that we could all agree upon was a critical skill for future work. During this time, I learned how to influence state policies. A year after our state passed our right to know law, the federal Occupational Safety and Health Administration promulgated the Hazard Communication Standard, which set a comprehensive approach to chemical risk information in the workplace including mandatory Safety Data Sheets, labeling, and worker training.

Continuing on with my education, I completed my Doctorate in Public Health at Johns Hopkins University School of Public Health where I gained really important knowledge and also met national and international leaders in environmental health. While doing my doctoral studies I worked for the United Steelworkers of America (USWA) on occupational health and safety where I saw the many ways in which our regulatory processes were failing both workers and the fence-line communities. I was also working for USWA during a time when many steel mills in the United States closed, as the steel industry went off-shore, putting hundreds of thousands of workers out of work. I watched whole communities implode from this impact, a painful but very important learning experience that I am currently applying to my work on "just transition"-how we plan for a transition from a fossil fuel-reliant economy to one that is based on renewable energy, as well as sustainable transportation and agriculture sectors and do it in a way that creates a safety net for workers and communities during the transition.

My job immediately following completion of my doctorate was directing the National Center for Hazard Communication at the University of Maryland College Park. In this context, I built a new degree program for environmental managers and completed a number of grant-funded studies on the efficacy of the tools and policies to provide workers and communities with information on hazardous chemical exposures. The results of these studies showed that we still were failing to effectively communicate risk for a variety of reasons including inadequate information from the manufacturers of toxic chemicals. A further indication about our chemical policy failures was the growing numbers of studies showing that humans were awash in toxic chemicals-in our blood, urine, and fatty tissues. Even our babies are being born "pre-polluted."

While my hazard communication work was very interesting and seemed important, I wanted to be more connected to the health professions community and took a faculty position at the University of Maryland School of Medicine, in Baltimore, where I established the Environmental Health Education Center and started working on lead poisoning prevention funded by the U.S. EPA. This work included training a range of people involved in the assessment and mitigation of lead-based paint in homes and schools, in addition to working with impacted communities. This work began to morph into more comprehensive healthy homes and healthy schools efforts and working with the EPA's IAQ/Tools for Schools Program which helped thousands of schools around the country assess and address environmental health risks.

One of my favorite grants was from the National Institute of Environmental Health Sciences to work with urban youth, almost entirely African-American, in Baltimore, on Environmental Justice. I loved working with the youth and learned many more lessons from them then they every learned from me. Their challenges and lived experiences helped to inform all of my future community engagement efforts. The grant lasted 5 years during which time we completed many neighborhood-level environmental health assessments, developed intervention projects, hosted a city-wide youth-led conference on Environmental Justice, the youth wrote and produced a play on the community's experience with lead poisoning, and implemented several research studies that resulted in published papers.

The young people were amazing and endlessly creative. They titled their conference Endangered Species: Our Urban Youth. The play the youth wrote and performed at the conference revolved around a family that included a single mom and two young children, one of whom was lead poisoned. The students' authentic depiction of greedy landlords who rented substandard, poorly maintained houses; a government that was not there to protect them; and a health system that was only marginally responsive to their health needs was heartbreaking, but also gave me the impetus to increase my engagement on policies and practices in Baltimore and in Maryland. Working with a vibrant coalition that included affected communities, we eventually helped pass the most stringent lead laws in the country.

During this same period, the U.S. EPA established a new Office of Child Health Protection and I served on their Federal Advisory Committee. This was an important time for considering the special vulnerabilities of the fetus and children to toxic chemicals and appropriate regulatory improvements to address these considerations. 
A key leader in that office was Elizabeth (Liz) Blackburn, a nurse who worked tirelessly to help translate science into regulations to protect children's health.

In the early 1990s, I started giving environmental health lectures in schools of nursing and, finding interest, looked to see what else was being done to integrate environmental health into nursing education. There was virtually nothing to be found. The Institute of Medicine had published a 1985 report on the inadequacy of environmental health in medical education, with associated recommendations, but no equivalent was available regarding nursing. In response to finding out about this report I and two colleagues from the University of Maryland went to the Institute of Medicine and asked that a similar study be developed for the nursing profession. They agreed and nurse leader Lillian Mood was asked to chair the study committee that produced the 1995 IOM Report, Nursing Health and the Environment. The recommendations from this report articulated four domains of nursing into which environmental health must be integrated (education, practice, research, and advocacy) and this framing has provided the lasting scaffolding for much of our subsequent environmental health and nursing work, and particularly our work in the Alliance of Nurses for Healthy Environments.

After 6 years at the School of Medicine I was visited by the Nursing Dean who asked me to bring my center to nursing which I did. I directed the Environmental Health Education Center in the School of Nursing for 20 years. I had many, many wonderful colleagues, staff, students, and collaborators and we worked on a great many educational programs, projects, studies, and campaigns. My first grant came from the Kellogg Foundation (\$1.4 million) to educate faculty about environmental health in the southeast quadrant of the United States-11 states. We worked closely with Dorothy Powell, the Dean of Howard University School of Nursing, a historically black university, and built on their great environmental justice work in the Mississippi Delta.

I subsequently got a federal grant from the Health Resources and Service Administration (HRSA) to develop an environmental health and nursing graduate program-the first in the nation. We built this on the existing Masters Degree in Community Health Nursing and it helped to launch several important nursing leaders, including Katie Huffling, the current Executive Director of the Alliance of Nurses for Healthy Environments, Robyn Gilden, nursing researcher and faculty member at the University of Maryland, and the late Denise Choiniere, who became the Director of Sustainability for the University of Maryland (650 bed) Medical Center.

In the 1990s, I was also involved in the founding of Health Care Without Harm (HCWH), which Charlotte Brody talks about in her profile found later in this article. During the first several years, when HCWH was more of a campaign than an organization, nursing colleague Susan Wilburn and I cochaired the Nurses Work Group and delivered a number of train-the-trainer programs, entitled RN No Harm, around the country helping nurses to green their hospitals. Yet again, from these efforts more nursing leaders emerged, including nurses who became directors of their hospital's sustainability efforts. At the time Susan Wilburn was the CoDirector of the ANA's Center for Occupational and Environmental Health where they were very proactive at protecting nurses' health and safety and addressing environmental health risks that were posed by health care practices. Regrettably, the Center has since been disbanded. Susan is currently doing international work through an international extension of $\mathrm{HCWH}$, Global Green and Healthy Hospitals.

In Maryland, we were able to raise funds from local area foundations and developed the Maryland Hospitals for Healthy Environments (MDH2E) which I directed. This was a multidisciplinary effort to address hospital purchasing, waste management, sustainable foods, and a great many other sustainability issues. We were supported by additional grants from the U.S. Department of Agriculture to work with local area farmers and directors of hospital dietary services to shift their purchasing to more local, seasonal, and sustainably grown food products. We also got USDA funds to start 12 farmers markets at hospitals that were often in areas of Baltimore City and known food deserts, where food insecurity-particularly regarding healthy food options-was a serious problem. And we hosted an annual MDH2E informational and networking conference that was attended by hundreds of hospital staff, nurses, facility managers, infection control staff, and others during which time we also gave our most promising change makers awards. Such recognition, and the associated press that we helped them to obtain, created positive incentives and sometimes even friendly competition to do even better the following year.

Over the years, we sponsored home-grown writers' workshops for nurses who were interested in writing about environmental health. These retreats often took place in extraordinary locations like the Northern California Coast and Martha's Vineyard. Some were at retreat centers but many of them were in nurses' homes and attended by nurses from all over the country. These were wonderful several-day, residential events where nurses supported each other in producing environmental health articles for a range of nursing publications.

With foundation funding, we developed a number of training and educational events and materials. For example, we convened representatives from several nursing unions and cocreated a compendium of sample union contract language for nurses to use during their contract negotiations on reducing/addressing chemical exposures in health care settings.

In 2008, we convened a meeting of 50 nursing leaders from around the country, some of whom were already active in environmental health but many who were not. Brenda Afzal, a senior nursing staff member at my Center was the main organizer of this remarkable and memorable event. The meeting was held on a ranch in the middle of nowhere, Oracle, AZ, where for 4 days we talked about the role that nurses should be playing regarding environmental health. There was agreement that to better coordinate our communication and our various efforts, we should form a structure which became the Alliance of Nurses for Healthy Environments (ANHE)-www.enviRN.org-whose mission is: 
Promoting healthy people and healthy environments by educating and leading the nursing profession, advancing research, incorporating evidence-based practice, and influencing policy.

Since the creation of ANHE, dozens of sponsored efforts have been supported-a national network of over 4,500 nurses now receives regular communications; various specific topic have been explored and addressed such as chemical policies, climate change, fracking, and agricultural impacts on health; an award-winning online textbook was created (e-Text); a Nurses Collaborative on Climate Change was launched; and an invitational meeting hosted by the White House was convened to discuss nurses' roles regarding climate change. The most recent accomplishment is the AHNE Environmental Health Nurse Fellowship in which 30 nursing fellows from around the country are being supported to work with local environmental justice communities. For each of the nursing domains, Research, Education, Practice, and Advocacy, ANHE has a Work Group that hosts regular calls and webinars.

Other milestones in the integration of environmental health into nursing that I have been involved in have included creating an "Environmental Health Standard" within the ANA's Scope and Standards of Professional Nursing Practice; creating an Expert Panel on Environmental Health within the National Academy of Nursing (which has since expanded to include public health) that has been creating position papers for nursing on national policies; the American Association of Colleges of Nurses created an Environmental Health Committee; and the International Council of Nurses adopted a position on Climate Change that over 130 national nursing organizations signed on to.

I am currently at the University of San Francisco and own an organic farm and vineyard in Northern California, but I am still quite busy being an ANHE Board member, active on climate change, food, and agriculture, and working on "just transition" efforts-getting us off of fossil fuel in a way that takes care of everyone who is impacted during the transition. Still teaching nurses about environmental health. Still going to the state house.

There are some things that "I" did regarding environmental health and nursing, but the vast majority of things "we" did. We have had some very generous funders over the years and a great many supporters. We have helped to birth nursing environmental health champions. I have been involved in over four decades of work that I hope is helping to form the next generation of nurses who will consider environmental health a critical component of the nursing profession. I am a firm believer that "The best way to predict the future is to design it" (Buckminster Fuller).

\section{4 | ADVOCACY}

\section{1 | Bright Futures}

\section{Charlotte Brody, RN}

Vice President, Health Initiatives of the BlueGreen Alliance
My parents came to the United States after WWII and I was born two years later. Like many other children of parents who immigrate to escape persecution, I grew up with the Statue of Liberty vision of America. This was the country where the huddled masses breathed free. This was where the government was for the people. This was where Congress passed laws to protect everyone's air, water, food, and the products we use every day. As a 10 year old, I remember sitting on the rug in front of the TV watching the Congressional hearing on dyes in food that eventually became the 1960 Color Additive Amendments. The food industry executive on the screen was explaining that the dye in maraschino cherries did not need to be restricted because no one ate more than one or two. As I watched his testimony, I was making my way to the bottom of what had been a full glass jar of those cherries and drinking the maraschino syrup mixed with soda water. It was fruit. There was no warning on the jar. With my tongue dyed red, I was a real life 10-year-old example of why the government needs to make sure that legal is the same as safe. I still believe that. And I still carry with me the gift and the burden of being the child of survivors. Those two pieces of my history combined into making me both a nurse and an activist. Alleviate suffering. Give everyone a chance at the dream. Prevent the harms that can be prevented. Stand up to bullies. Empower your patients and everyone else with the tools they need to protect themselves and their families. And create and defend government programs that help make all of these things more possible.

I grew up in the time of white flight from Detroit. From my suburban home, I watched the evening news coverage of the Civil Rights Movement in the South. I do not think I thought about it then, but now I believe that I felt that standing up to racism was like standing up to the Nazis that had cost me aunts and uncles and cousins and grandparents. After a boy I knew from summer camp took me to my first picket line, with my friend Shelley, I took the bus downtown and became a volunteer with SNCC, the Student Non-Violent Coordinating Committee. Two extraordinary women, Dorothy Dewberry and Martha Kocel ran the Detroit Friends of SNCC office. They took me in. They let me type thank you letters. When they found out I was good at arithmetic, my duties included balancing the check book. I got to be in the room when protests and fundraising events were planned, and problems worked out. And I have tried to be in some version of that room ever since. Those rooms have included the 1970s women's movement and protests against the War in Viet Nam during college. Wanting to do more than protest and recognizing that the soldiers who fought were not responsible for the decision to start the war, I spent a year outside Fort Campbell, Kentucky working with soldiers just back from Viet Nam. At the end of that year I decided to go to nursing school. I needed a way to support myself that my liberal arts education did not provide. But the decision to become an RN was also based on a growing sense that I could be most useful doing what I could to improve the health of people and the world they live in. I have never thought of myself as an environmentalist. I am a nurse. If coal dust is destroying the lungs of coal miners, if 
cotton dust is doing the same to cotton textile workers, if mercury is coming out of incinerators and getting into breast milk, then what can I do to help solve that problem? I recycle. I bring my own bags. In cities, I take public transportation and I walk. But the things that I have done that I am most proud of have been environmental accomplishments that can be measured as improved health to people. And because it is all connected, healthier people can mean healthier wildlife and a healthier planet. Remember mercury thermometers? And sphygmomanometers? Mercury is a potent neurotoxin that has no safe level of exposure. In utero and early life exposures are especially dangerous. When a mercury-containing device breaks or leaks, it volatilizes and exposes everyone in the vicinity. The same thing happens when you put a mercury-containing device into an incinerator. When I served as the Co-Director of Health Care Without Harm, with the leadership of Duluth Civil Engineer Jamie Harvie, we began the effort to phase out the use of this neurotoxic chemical in medical devices. No less an opponent than the Mayo Clinic attacked our work, explaining the mercury sphygmos were the gold standard and that patients would die if we took them away. My nursing experience had taught me that many health care professionals were unskilled in the art of blood pressure measurement with or without a mercury containing device and that calibration was needed for all measurement tools. Today the Mayo Clinics and almost every other hospital in the United States have phased out the use of mercury-containing devices. Under the Minamata Treaty, signed in October 2013 and entered into force in August 2017, mercury-based measuring devices will be phased out of global production and use by 2020 . That is next year. The effectiveness of the market and government actions that led up to the Minamata Treaty can already be measured as lower average levels of mercury in blood and breast milk around the world. Less mercury means more babies with fully developed and functional brains and nervous systems. Less mercury also means healthier loons and other animals that eat fish. And healthier fish too. One big reason for the drop in mercury in the United States was the shutdown of more than 2,000 inefficient medical waste incinerators. I helped make that happen first at the Center for Health, Environment and Justice and then at Health Care Without Harm. The work that HCWH began on phthalates in polyvinyl chloride (PVC) medical devices led to my helping to form the Campaign for Safe Cosmetics. In that campaign, we encouraged many companies and shamed others to move away from the use of dangerous chemicals like phthalates, toluene, and formaldehyde in personal care products.

For the last 10 years, I have circled back to my earlier work with coal mining families and cotton textile workers and serve as the Vice President for Occupational and Environmental Health for the Blue Green Alliance. BGA unites America's largest labor unions and its most influential environmental organizations to solve today's environmental challenges in ways that create and maintain quality jobs and build a stronger, fairer economy. At BGA, I have built a chemical information web site www.ChemHAT.org, created a worker-trainer delivered curriculum about the chemicals linked to breast cancer called Putting Breast Cancer Out of Work, and been on the team that won the country's strongest health and safety regulation for refineries in California. My career has had some purposeful meanderings. Along the way I directed a Planned Parenthood Affiliate and helped to organize the Brown Lung Association. I helped to launch the Campaign for Safe Cosmetics, participated in the national Safer Chemicals/Healthy Families Campaign, and worked for Green for All.

I have also been lucky enough to be part of the founding of Healthy Babies Bright Futures, a new national campaign to lower the levels of chemicals that are harming neurodevelopment. As the child of Holocaust Survivors, I know I was lucky to be born. And I have tried to pass that luck on by finding ways to decrease the harm that chemicals pose to the health of people and the planet. Not every idea has worked. But it is always seemed very nursery and so very appropriate to keep trying out new ideas, learning from your mistakes and developing your skills to take on the next challenge.

\subsection{Kitchen Table Wisdom}

\section{Lillian Mood, RN, MPH, FAAN}

Chair, Institute of Medicine Study Committee and Co-Editor of the IOM Report: Nursing, Health \& Environment

From my first public health nursing course in a brand-new baccalaureate program in 1958, I was taught that public health is a team effort. No one discipline alone can "assure conditions in which people can be healthy." (IOM, 1988, p). Attention to environmental contributions and risks to health was reinforced by cross-discipline curricula and practice sessions in my graduate program in a new University of South Carolina School of Public Health in 1975. With a focus on epidemiology, it was hard to miss that environment was one of the three key elements in prevention and intervention in diseaseagent and host the other two points on the epidemiology triangle.

My entire public health career was in the S.C. Department of Health and Environmental Control, where traditional environmental sanitation programs and EPA-delegated responsibilities for air, water, and waste management were housed side by side with programs addressing communicable and chronic disease, maternal and child health, home health care, and medical facility licensure and certification. The local health departments were units of the state department charged with maintaining accepted standards, equitable coverage, geographic collaboration, and sharing of staff in emergencies, such as disease outbreaks and hurricanes. The structure for my public health practice reinforced that "Healing people and healing the planet are part of the same enterprise." (Roszak).

After several years on the agency's executive management team, as Assistant Commissioner and State Director of Public Health Nursing, with colleagues from each major department division, I was asked by the head of environmental programs to transfer to his Deputy area because, in his words, they "needed a nurse." He described the need for someone who could bridge the gap between the staff of engineers and environmental scientists 
and communities who were concerned, upset, and angry over situations where citizens believed something in their environment was threatening or affecting their health. Thus began the final third of my public health career developing a network of professional colleagues, community activists, and everyday citizens as we responded to and tried to prevent environmental hazards to the health of the population.

My developing role as Director of Risk Communication and Community Liaison was an exciting and challenging adventure! I spent much of my time initially with the front-line environmental staff, letting them show me what their work involved so I could explain and interpret their efforts to protect health through protecting the environment and, at the same time, building trusting relationships. I learned a whole new vocabulary and many new concepts. My teachers expanded across the nation as I implemented an individual learning plan supported by a Kellogg Foundation Fellowship in Community Leadership Development and participated in EPA conferences and on a sub-committee of the National Environmental Justice Advisory Committee, established by President Clinton's Executive Order.

Many of my working hours were spent at kitchen tables, in country churches, and neighborhood associations-wherever individuals and communities gathered to tell me and show me what was of concern to them. Sometimes it was the look or smell of water or air. Sometimes the "smoke" from a nearby industrial plant alarmed them. Sometimes it was their noticing that "too many people are sick in this neighborhood" or "too many people around here have cancer." My job was to look and listen and return to my agency to participate in developing an appropriate response. Often that consisted of sharing information that the agency had but the public was not aware of or did not understand. Sometimes an environmental investigation was indicated.

The team involved in the response included whoever had something to contribute or a stake in the issue: the environmental experts, professionals from epidemiology, disease control, the cancer registry, local health directors and their staffs, always keeping the communications open and transparent with the involved communities. We were all learning every day the truth of the \#1 principle of the environment: Everything is connected to everything else.

In other situations, our staff had information that needed to be conveyed to communities, for example, an environmental spill or other discovered hazard, an industrial permit application or renewal request. In those cases, my job was to work with the affected community to find the best way to inform them and to keep them up-to-date on progress and facilitate opportunities for their input and questions.

My fairly unique role (at the time) opened doors to involvement with EPA initiatives as well as a growing interest in closer connections between environmental and public health organizations, such as the American Public Health Association. I participated in "immersion environmental education" with local public health staff volunteers to strengthen our ability to respond in communities. Our agency, in partnership with the Urban League, sponsored a very successful Future Search Conference on Environmental Justice that involved intensive work among varied stakeholders-environmental regulators, community activists, industry representatives, educators, elected officials-seeking to find common ground. I was on the Advisory Board for a significant initiative developing and training local teams for emergency response.

I was often invited to tell the story of my work at professional meetings and conferences, and ultimately was asked to chair the Institute of Medicine Study Committee on Nursing, Health \& Environment. The report from that study was published in 1995 and provided a framework for nurses in practice, education, research, and advocacy. The Alliance of Nurses for Healthy Environments emerged as a stellar organizational strategy for strengthening the contributions of nurses in environmental health roles.

Life and commitment do not end with retirement! Most of my volunteer efforts since 2001 involve ways of making our environment (both built and natural) more supportive of healthy living. My major focus is better public transportation, which translates into access to jobs and health services, cleaner air and water, fewer traffic deaths and injuries, and reduction in the stress of traffic congestion and commuting. Related community involvement for me is in advocating for safe walking and biking spaces and planting trees, including a project with local high school students planting sequoias-magnificent trees that are amazing carbon absorbers! And underlying any specific policy initiative is my commitment to a constructive, functioning democracy, which means volunteering with the League of Women Voters in voter registration, voter participation, informing voters on issues, and implementation of fair voting districts.

In all of these wonderful experiences, the solid truth I first learned so many years ago was reinforced over and over: It takes all of us working together to maintain and improve the public's health, and protecting the environment is indispensable and intimately integral to that goal.

\subsection{Elevating the Nursing Voice}

\section{Katie Huffling, MS, RN, CNM, FAAN}

Executive Director, Alliance of Nurses for Healthy Environments

I stumbled into environmental health nursing quite by chance. I was in the master's program at the University of Maryland Baltimore working on my nurse-midwifery degree and Dr. Barbara Sattler gave a guest lecture on environmental health in one of the required Masters' classes. In a room of 40 or 50 students, I was the only one who raised my hand when asked if we routinely buy organic foods. I was shocked that these smart nurses, many with children, did not have organic foods on their radar. In my household growing up, my mother had been an early adopter of organic and whole foods, so I did not even question buying organic when possible. It was just ingrained in me.

After the class, I approached Dr. Sattler and asked how I could help my fellow nurses make the connection between environmental exposures and health. Dr. Sattler was very generous and worked with me on an independent study course that summer and I was 
hooked! She eventually hired me as a research assistant through the rest of my nurse-midwifery program, where I had the amazing opportunity to work with environmental nurse health leaders such as Brenda Afzal, work on a project engaging communities impacted by superfund sites and how the sites could be reused after clean-up, and the development of an interactive web site on all things environmental health nursing.

As I began my midwifery career, and the more I learned about how environmental toxins impact pregnant women and the growing fetus, the stronger my desire to expand my environmental health work grew. How can we support our patients to be able to become pregnant when they want to be when they are being exposed to environmental toxins every day that can have negative impacts on fertility? And how can we provide them with the support they need to have healthy pregnancies and healthy babies, when they are being exposed to toxic chemicals in their shampoo and cleaning products and being exposed to air pollution that could lead to preterm delivery or low-birth weight babies? To help address this I developed the first of its kind assessment tool for use in my midwifery practice. This tool asks simples question on lifestyle and exposures, provides context on why we were asking those questions, what the patient can do to reduce exposures, and had a spot to check if they wanted to talk with their provider about a particular question. This tool has now been used in ob/gyn practices across the country.

After several years working as a staff nurse-midwife, and then as assistant director of my practice, I had the opportunity to work for the newly formed Alliance of Nurses for Healthy Environments (ANHE) full time. I jumped at the chance. While I cherish the one-onone interactions with my patients, I felt that I could make a difference on a larger, population scale working for ANHE.

Over the past 9 years, I have had the privilege to work with a phenomenal group of nurses and nursing organizations to expand nursing knowledge and engagement on all things environmental health. Some of what I am most proud of, and have had the most fun doing, is around policy and advocacy.

When I first started with ANHE I had very little experience in the advocacy realm. But, luckily I was able to learn from and work with nurse Kathy Curtis, the executive director of Clean and Healthy New York. Under her tutelage, I was able to learn how to effectively organize nurses, work in broad coalitions for large scale policy change, and how to win.

One of the first campaigns I worked on was to update the Toxic Substances Control Act (TSCA) so that the U.S. Environmental Protection Agency would have the ability to actually regulate toxic chemicals and require premarket safety testing before chemicals came on the market. ANHE was the only nursing organization on the steering committee of the Safer Chemicals, Healthy Families Coalition. Through our outreach, 17 state and national nursing organizations became members of the coalition. The nursing perspective was critical in engaging policymakers around TSCA legislation and educating them on the link between chemical policy and health.
One of our first successes was having a key U.S. Senator signing on to our bill as a cosponsor after meeting with me and two other nurses. When nurses speak from the heart and with the science, policymakers really do stand up and take notice! While the final bill that passed was not as strong as we hoped, ANHE has continued to participate in the rule-making process and is currently a litigant in a lawsuit against the EPA concerning implementation of the updated TSCA.

For a number of years ANHE has been active in educating nurses and the public on the health impacts of oil and gas extraction. In Maryland, ANHE was a founding organization of the health coalition, Concerned Health Professionals of Maryland. This coalition was formed to elevate the health professional voice in the Maryland anti-fracking movement, which was looking to keep this form of oil and gas extraction out of the state. Through this coalition, nurses were vocal about the health impacts of fracking and provided testimony at hearings, spoke at press conferences, wrote to our local newspapers, and consistently educated state policymakers on the health impacts of fracking. Our efforts were instrumental in the passage of a fracking ban in 2017.

ANHE has been increasingly focused on climate change due to its significant threat to public health. With my leadership, ANHE has become the go-to organization for issues related to climate change, health, and nursing and nursing's recognition as a leader in this movement continues to grow. We have held workshops for nurses in a number of states and in Washington, DC that include advocacy training followed by meetings with their legislators. It is so amazing to watch nurses grow into powerful advocates over the course of several meetings. They begin to realize that as nurses, the most trusted profession, policymakers want to hear what they have to say. We now have ANHE nurses routinely meeting with legislators, providing testimony at EPA hearings, and participating in climate marches. Through our collective efforts I feel very strongly we can make a difference and turn our country and our world back from its current destructive trajectory.

We were also recognized by the Obama Administration as a key constituency in addressing climate change. In 2016, I worked closely with the Obama White House to hold a historic Climate Change, Health, and Nursing Roundtable. We had representatives from 16 national nursing organizations at the event, where we discussed how nursing could be an instrumental force in addressing climate change. From this meeting the Nursing Collaborative on Climate Change and Health was formed. The Collaborative now has 12 member organizations who work collectively to elevate climate change as a health priority. Member organizations are leaders in engaging policymakers, educating nurses on climate change and health, and providing opportunities for their members to take climate action.

Through my climate change work, my immense pride in being a nurse has only strengthened. With our holistic perspective, nurses are perfectly poised to be leaders in the climate movement, and I cannot wait to see what impact my work, and the work of ANHE has on the health of mother earth. 


\subsection{Woman Is The First Environment}

\section{Tekatsi:tsia'kwa Katsi Cook, Wolf Clan Mohawk \\ Founder, First Environment Collaborative}

Co-founding member, National Aboriginal Council of Midwives

I am an advocate for the preservation and restoration of Indigenous midwifery, and a renowned voice for community-driven environmental and reproductive justice health research and practice. My work spans many worlds and disciplines and demonstrates a lifelong career of advancing the superlatives if Indigenous Wisdom and Knowledge through the strengthening of Aboriginal midwifery.

Using my voice as an Indigenous environmental reproductive health activist, scholar, and autochthonous elder midwife, my greatest contribution to Environmental Health has been the modeling of a community- and culture-based participatory approach. This purposeful approach advances Environmental Health and Environmental Justice practice, research, and knowledge translation at the nexus of Reproductive Health and Reproductive Justice in the Six Nations Haudenosaunee communities based on our traditional principles of respect, equity, and empowerment.

Strengthening Indigenous women's self-determination through respect, equity, and empowerment requires the democratization, production and intergenerational transfer of Environmental Reproductive Health knowledge within Indigenous communities. This knowledge must be translated through Indigenous languages and worldviews, and situated within the kinship and cultural bodies of the individual and her clan and nation.

From the episteme that Woman is the First Environment, I worked to advance Environmental Health and Environmental Justice at the nexus of Reproductive Health rights aligned with Human Rights standards such as right to culture, right to health, right to security, and right to justice.

I became involved in environmental issues in the early 1980s, when the General Motors site that lay directly adjacent to the Mohawk community was declared the largest PCB Superfund Site in the United States. A mother in my care asked if it was safe to breastfeed. She was concerned about the impact of industrial pollution on her breast milk production. Her good question sent me on a quest for answers, one that would shape my entire career and seed a new field of Indigenous health research.

I organized the Akwesasne Mother's Milk Project in 1981 to build relationships and create meaningful partnerships with project participants, other community members, researchers, scientific partners, and health care providers-including key Mohawk nursesto determine the impacts of toxic industrial chemicals on the bodies and breast milk of Mohawk women through fish consumption. This foundational work engendered over 30 years of multigenerational human health research in my community (Hoover, 2017).

In my practice as a traditional Mohawk midwife, I promoted the idea that Woman is the First Environment. I drew from wisdom and teachings passed on to me by Mohawk elders, including my paternal grandmother who delivered me in the big white iron bed of her farmhouse on the reservation in the early 1950s. The orality and experience of the elders drawing their lives from the land and the Saint Lawrence River is my inspiration that woman is the first environment.

I have written (2016, p.1):

Woman is the first environment. In pregnancy our bodies sustain life. At the breast of women, the generations are nourished. From the bodies of women flows the relationship of those generations both to society and the natural world. In this way the earth is our mother, the old people said. In this way, we as women are earth.

It is at this most critical window of development in the mother's body-the child's first environment, first experience, and first relationship-where the embodied wealth of Indigenous nations is determined.

One Mohawk word for midwife is lewirokwas, pronounced yehwee-loh-gwus. I have been told by Marita Thompson, an early collaborator as research associate for First Environment Partnerships for Communications (NIEHS), that the word lewirokwas means "she's pulling the baby out of the water, out of the earth, or a dark, wet place." Such an ecosystemic view deepens our understanding that the earth, waters, and bodies of women are one.

Mohawk language and culture is the inspiration behind my work. I draw spiritual energy from my Mohawk language in which right relationship is described in metaphor, in imagery, and symbolism. My greatest collaborators have been the fluent speakers of our language, the practitioners of our sacred ceremonies, and the powerful Saint Lawrence River itself. We call it Kaniatarowanénhne or "Big River." One of my greatest collaborators, Kanienkéha Bear Clan Mother Wakerakats:teh Louise Herne, describes the long winding channel as "moving like a snake, referring to a place almost past tense." The Mohawk name of this historic river addresses the convergence of three other rivers where the community of Akwesasne is situated. Its be-ing has many currents and crosscurrents, in some places the river flowing in both directions. The Saint Lawrence River, in whose memory we Akwesasronon live, work, play, and pray, is contaminated with a whole host of industrial chemicals that have made their way into our bodies, including our first medicine, mother's breast milk.

There are a lot of multidisciplinary ways to talk about this injury and insult to the sacred homelands of our generations of Akwesasronon. I feel that a new generation of nurses working at every level of practice must deeply identify themselves within their own, personal sacred homelands. Start with walking barefoot upon Mother Earth, stomping your feet to call your own spirit into your bones and body. Root yourself. As a young activist for Indigenous self-determination, I began with the idea of our Women's Dance in the longhouse as I worked out of the Red School House Survival School in St. Paul, Minnesota in the late 1970s. The Women's Dance honors the intimate relationship of women to earth mother, as our feet caress her. Like her, we have many responsibilities to life. Practice begins with a call to concepts. What concepts will you use to carry the generations forward in good health and well-being? 
Unleashing the potential that exists within the North American Indigenous world is the impetus behind my lifelong work. After decades of connecting people, purpose and initiatives, I founded and direct Spirit Aligned Leadership program to elevate the lives, voices, and dreams of North American Indigenous women elders who have worked to heal, strengthen, and restore the balance within their Indigenous communities (Spirit Aligned, 2018).

\section{5 | PRACTICE}

\section{1 | Greening Our Practice}

\section{Dr. Beth Schenk, PhD, MHI, RN-BC, FAAN \\ Providence-WSU Nurse Scientist/Sustainability Coordinator for Providence St. Patrick Hospital in Missoula, MT}

The sunset from a fire tower in southern Missouri had struck me in its glorious, ineffable beauty, and I started crying. I was about 7 years old. My parents tried to console me, but I could not explain my feeling. I could not explain it until many years later when I recognized this feeling in other settings. The world, in its mystery, complexity and beauty breaks my heart: it is almost too much to comprehend, to absorb. Sometimes I cry, with profound appreciation for this planet that carries all of us, human, plant, and animal, across time.

A few years later, around age 10, I was entranced by the concept of "ecology." I saw the word and pondered what it might mean. Concerned about the natural world I was already in love with, I started a group called the AP's, the Anti-Pollutionists. My band of friends and I created a neighborhood carnival with lawn-mower rides and cookie sales. Our kind parents dunked for apples and played our silly games. We earned a little money, enough for the city to purchase two trees. That was great and all, but another lesson learned was that to save the world, more firepower was needed.

Later yet, in high school, I studied the remarkable ability of water hyacinths to uptake heavy metals. An advanced chemistry class gave me an opportunity to spend a semester measuring aliquots of fluid from water where hyacinths were growing, to see if heavy metals decreased over time, which they did. Then in college, I studied botany, wilderness studies, and philosophy. My environmental ethic was getting hard-wired by now.

After graduating, I worked in field studies for two seasons, but I knew I wanted to work with people more. I thought back to when I worked as a nursing assistant after high school. I remember enjoying caring for patients though what had struck me was how much I liked and respected the nurses. Sensible, smart, and kind, they had solutions for everything. I thought I might like to be a nurse, at least for a couple of years.

After I got over the shock of being responsible for more than any young graduate should, of facing death and suffering, and slowly developing ways not to be overwhelmed, I began to look around. With horror I was appalled at the waste of resources and the actual waste-the garbage we threw out. At that time, in the 1980s, we had not heard yet of climate change; we did not know of the ubiquity of toxic chemicals; we did not know that modern agriculture was harming our health. But we could see the waste. I had already developed a minimal-waste mentality, going out of my way to recycle and reuse. The single-use culture of health care offended me.

So, I began one of many efforts to recycle and reduce waste. My first bona-fide success, with a budget and a plan, was almost 30 years ago. Ever since, I have been working to decrease the environmental impacts of health care. Although I had successes, year after year I was swimming upstream through countervailing currents. Not many in health care shared my passion 30 years ago, it required constant convincing and prodding. Persistence.

Over time my experience, knowledge and clarity increased. It led to an expansion of environmental stewardship, including energy conservation, greenhouse gas tracking, waste segregation and reduction, sustainable food, Community Supported Agriculture (CSA) and gardens, working outside of my own hospital across a region and large health system. It led to more education, including a master's degree in health care innovation, and a PhD in nursing, studying the environmental impacts of health care. For my dissertation at Washington State University, I developed and tested the NEAT (Nurses' Environmental Awareness Tool). I developed curricular modules for including environmental health education. I developed the EWT-E (Energy/Water, Waste, Toxicants, and Engagement) wheel for environmental sustainability assessment.

Earning a doctorate opened many doors. Opportunities emerged to address environmental stewardship in the large 50-hospital health system where I practice (Providence St. Joseph Health). Climate change by then was seen as a pressing health issue, and I was able to respond at the university, in public education, in research and writing, and in mitigation actions both in the hospitals and in communities. I began serving on the board of the Alliance of Nurses for Healthy Environments; was a founding member of the executive council for Climate Smart Missoula, a unique organization leading my region toward climate health; and a founding member of Montana Health Professionals for a Healthy Climate. With other colleagues I supported the development of the Nurses' Climate Challenge (a collaboration between Health Care Without Harm and the Alliance of Nurses for Healthy Environments), and led the development of the Climate, Health, and Nursing Tool (CHANT). Most recently, I developed a new framework for environmental stewardship in nursing, the WE ACT, PLEASE framework.

As a basis for this framework, the foundational documents of our profession provide sturdy underpinnings. As nurses, we are obligated to "practice in an environmentally safe and healthy manner" (Standard 17 of the Standards of Professional Nursing Practice); to consider the health of the public, no matter where we practice; and to serve even in hazardous conditions, like those we see with climate change. Nursing is a practice discipline, whether in the hospital or clinic, the community, parish, university or any of many settings where nurses practice. Guided by a principle of doing no harm, how we practice matters to our patients, families and communities, to the outcomes we measure, and to our own satisfaction and pride.

Given the growing urgency of addressing our current environmental crisis and our professional obligations as nurses, we are at 
the point of the spear. As the most trusted profession and the single largest group of health professionals, we can impact change. We are obligated to impact change in our own practice; after all, that is our commitment to society. Furthermore, we have opportunities to impact change to build resilient cities, to serve as elected officials, to write and teach and encourage others. These are things we are good at, based on our powerful voice and compassionate pragmatism.

Although I thought I might be a nurse for a few years, I am going on 35. The love and respect I felt for the nurses I met early in my working years has only been reinforced by shining leadership of nurses I have known through my career. It is the same; they are sensible, smart, pragmatic, deeply committed, and able to handle complexity and contradictions with a shrug and a smile. Nurses bear the soul of caring. With strength and calm, a reassuring knowing, nurses offer a place to rest one's burdens for a moment and then get on with the work at hand.

Every day, more nurses are recognizing the pain of the damage we are causing to this planet, the one that shows us its marvels and secrets, and the one on which we depend. I am heartened by the persistence of nurses and their dogged determination to help, to heal, to care, and to apply balm to our wounded but beautiful and inspiring world. [Correction added on 20 January 2020, after first online publication: the duplicate sentence in this paragraph was removed.]

\section{6 | FOR MORE INFORMATION AND INVOLVEMENT}

The Alliance of Nurses for Healthy Environments (ANHE) is the only national nursing organization working at the intersection of health and environment. Its working groups, webinars, newsletter, podcast, educational topics and advocacy efforts help nurses to network, building coalitions and conversations, as they lead this work. The organizations web site, www.envirn.org houses many resources and opportunities for engagement, including the Nurses' Climate Collaborative, the Nurses' Climate Challenge, the Climate, Health and Nursing Tool, Nurses' Drawdown, and many others. Please explore, and get involved, as nurses apply their skills and knowledge to address the pressing environmental health challenges of our day.

\section{ORCID}

Patricia G. Butterfield iD https://orcid.org/0000-0002-9149-5218 Katie Huffling (iD https://orcid.org/0000-0002-5512-9667

\section{REFERENCES}

Hoover, E. (2017). The River is in us: Fighting toxics in a Mohawk community. Minneapolis, MN: University of Minnesota Press.

Institute of Medicine. (1988). The future of public health. Washington, D.C.: The National Academies Press. https://doi.org/10.17226/1091 Spirit Aligned Leadership Program. (2018). Our Story. Retrieved from http://www.spiritaligned.org/our-people/.

How to cite this article: Pollitt P, Sattler B, Butterfield PG, et al. Environmental nursing: Leaders reflect on the 50th anniversary of Earth Day. Public Health Nurs. 2020;37:614625. https://doi.org/10.1111/phn.12703 